\title{
MODIFIED ONE ZONE MODEL FOR FIRE RESISTANCE DESIGN OF STEEL STRUCTURES
}

\author{
Chao Zhang ${ }^{1, *}$ and Guo-qiang $\mathrm{Li}^{2}$ \\ ${ }^{1}$ College of Civil Engineering, Tongji University, 1239 Siping Road, Shanghai 200092, China \\ ${ }^{2}$ State Key Laboratory for Disaster Reduction in Civil Engineering, 1239 Siping Road, Shanghai, China \\ *(Corresponding author: E-mail: 08_chao_zhang@tongji.edu.cn)
}

Received: 23 February 2012; Revised: 8 July 2012; Accepted: 13 July 2012

\begin{abstract}
A modified one-zone model has been proposed for structural fire safety design. In the model, a quantity which considers the heat sink effect of steel members in fire compartment is added to the heat balance equation for one-zone compartment fire model. In this paper, the proposed model is solved by FEM simulations. The results from FEM simulations are verified by program OZone (V2.0). Case studies have been conducted with investigating parameters including number of steel members, compartment dimension, opening area, fire load density and steel insulation thickness. The results of the studies show that for fire compartments with bare steel members, the steel heat sink effect is greater for compartments with smaller floor area, larger opening, lower fire load density, and more steel members; and for fire compartments with insulated steel members, the steel heat sink effect is greater for compartments with larger floor area, smaller opening, higher fire load density, and more steel members with thinner insulation. Correspondingly, the over-predictions of the maximum steel temperatures by the current model are comparatively more severe for those compartments. The proposed model can yield more economical fire resistance design than the current model, which is recommended for practical usage.
\end{abstract}

Keywords: Temperature calculation; Steel structures; Post-flashover fires; Fire resistance; Modified one-zone model

\section{INTRODUCTION}

Currently, performance-based method is very popular in fire safety engineering. In a performance-based fire resistance design, the temperature of building components exposed to the potential real fires should be determined scientifically.

The behavior of a real fire is complex, which depends on many parameters such as sprinkler, fire load, combustion, ventilation, compartment size and geometry, and thermal properties of compartment boundaries [1]. So far, with increase in complexity, empirical correlations (e.g. nominal fire curves and parameter fire curve [2]), zone models (e.g. one-zone model for post-flashover fires [3,4] and two-zone model for preflashover fires [4,5]), and sophisticated CFD models (e.g. Fire Dynamic Simulation [6]) have been developed to model the fire behavior.

In fire resistance design, post-flashover fires are usually considered because they provide the worst case scenario (however, localized heating of key elements of structure in pre-flashover fires must also be considered). The temperature of a steel member exposed to a post-flashover fire is usually determined by first representing the fire environment by a fire curve obtained from solving the one-zone compartment fire model, then substituting the fire curve into a one-dimensional (1D) condensed heat transfer model to obtain the steel temperature [7]. The temperature of steel members in a fire can also be determined by advanced compute simulations [8].

Figure 1 shows the one-zone compartment fire model. In this model, the heat balance equation within the compartment is given by [9]

$H R R=\dot{q}_{g}+\dot{q}_{w}+\dot{q}_{o, c}+\dot{q}_{o, r}$ 
where $H R R$ is heat release rate due to combustion; $\dot{q}_{g}$ is rate of heat storage in the gas volume; $\dot{q}_{w}$ is rate of heat loss through the walls, ceiling and floor; $\dot{q}_{o, c}$ is rate of heat loss due to replacement of hot gases by cold; and $\dot{q}_{o, r}$ is rate of heat loss by radiation through the openings. Based on this model, both analytical expressions and compute programs were developed to give fire curves for structural design [10].

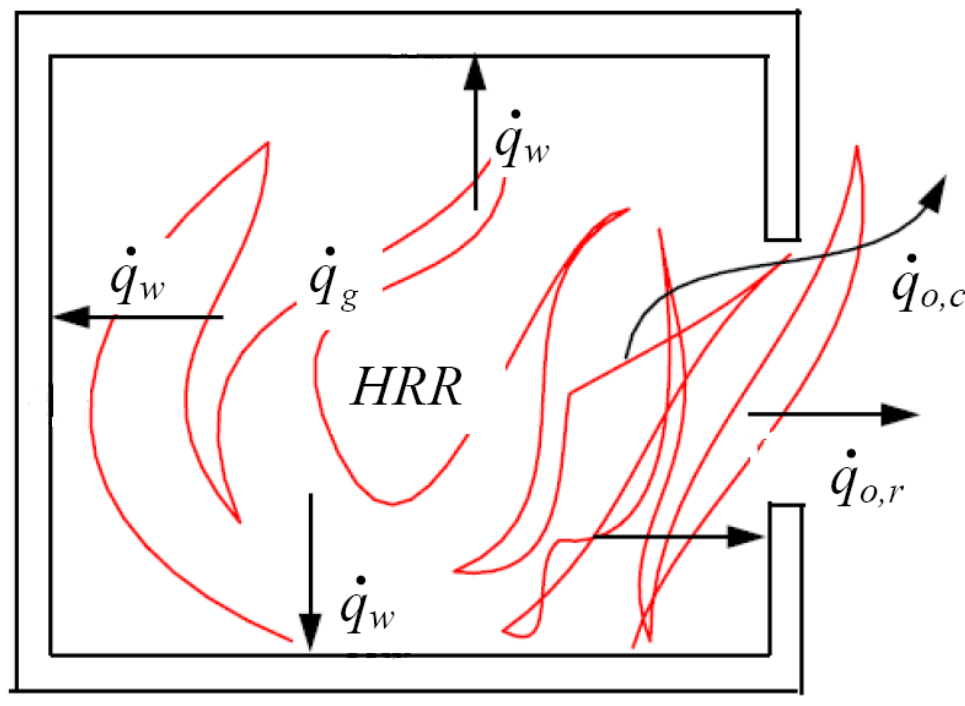

Figure 1. Illustration of Compartment One Zone Model

Figure 2 shows the 1D condensed heat transfer model used to calculate the temperature of insulated steel members. The temperature specified by a fire curve $\left(T_{f}\right)$ is interpreted as the effective black body radiation temperature for radiation calculation and as the same gas temperature for convection calculation. The radiation and convection effects are considered by using a thermal resistor $R_{f}$. The heat insulation effect of the fire protection is considered by using a thermal resistor $R_{i}$ ( for bare steel members without fire protection, $R_{i}=0$ ). The internal steel is represented by a lumped mass that temperature gradient within the steel is ignored. Based on this model, using various mathematical techniques, different formulas were developed for calculating the average steel temperatures [7].

It is obvious that the steel members in a fire compartment will absorb a portion of the energy released by combustion. That portion of energy will heat the steel members on one hand and cool the compartment on the other hand. As a result, the temperature of a steel member within a fire compartment is dependent on the heating mechanism of the compartment. However, in current models, as shown in Figures 1 and 2, the temperature of a steel member within a fire compartment is related to the fire curve which is determined without considering the heat sink effect of the steel member. 


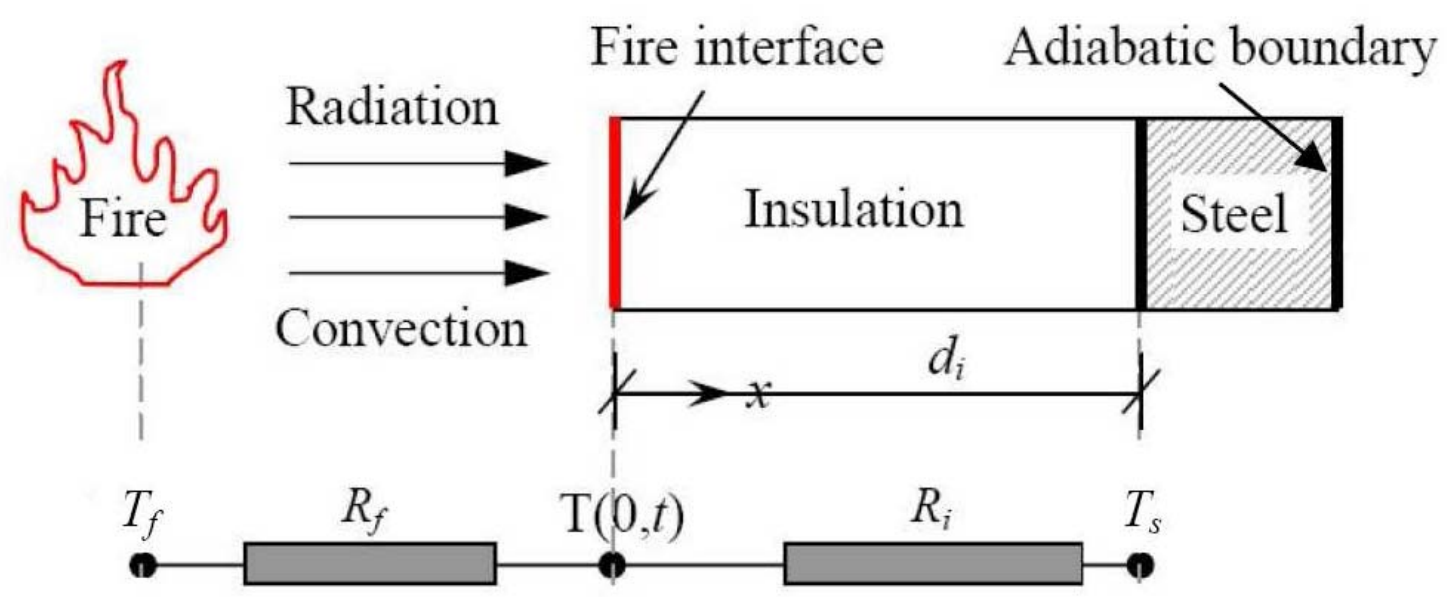

Figure 2. Illustration of 1D Condensed Heat Transfer Model

In this paper, a modified one-zone model is proposed to calculate the temperature of steel members in post-flashover fires. By the model, heat sink effect of steel members in fire compartment has been investigated.

\section{THE MODIFIED ONE-ZONE MODEL}

\section{$2.1 \quad$ Heat Balance Equation}

In the modified one-zone model, the heat sink effect of steel members in fire compartments has been considered by adding a quantity to the heat balance equation for one zone compartment model (Eq. 1), thus

$$
H R R=\dot{q}_{g}+\dot{q}_{w}+\dot{q}_{o, c}+\dot{q}_{o, r}+\dot{q}_{s}
$$

where, $\dot{q}_{s}$ is rate of heat storage in steel members.

\section{$2.2 \quad$ Sub-models}

\subsubsection{Heat release rate (HRR)}

Heat release rate $(H R R)$ is the most import variable in measuring fire severity, which can be calculated by

$H R R=\dot{m}_{f} \Delta H_{c}$

where, $\dot{m}_{f}$ is the mass burning rate of the fuel; and $\Delta H_{c}$ is the net heat of combustion of the fuel. In ventilation controlled fires (fully-developed compartment or post-flashover fires), the HRRs are alternatively calculated by [1]

$H R R=\dot{m}_{\text {air }} \Delta H_{\text {air }}$ 
where, $\dot{m}_{\text {air }}$ is the mass rate of air inflow and $\Delta H_{\text {air }}$ is the heat released per unit mass air consumed.

The HRR of a real fire can be measured by cone calorimeter designed by Babrauskas et al. [11]. In design work, the natural fire safety concept (NFSC) is widely used to represent the fire conditions $[2,4]$. As shown in Figure 3, the NFSC fire is assumed to be t-sqaure in the growth stage and decay stage begins at the time when $70 \%$ of design fire load is consumed.

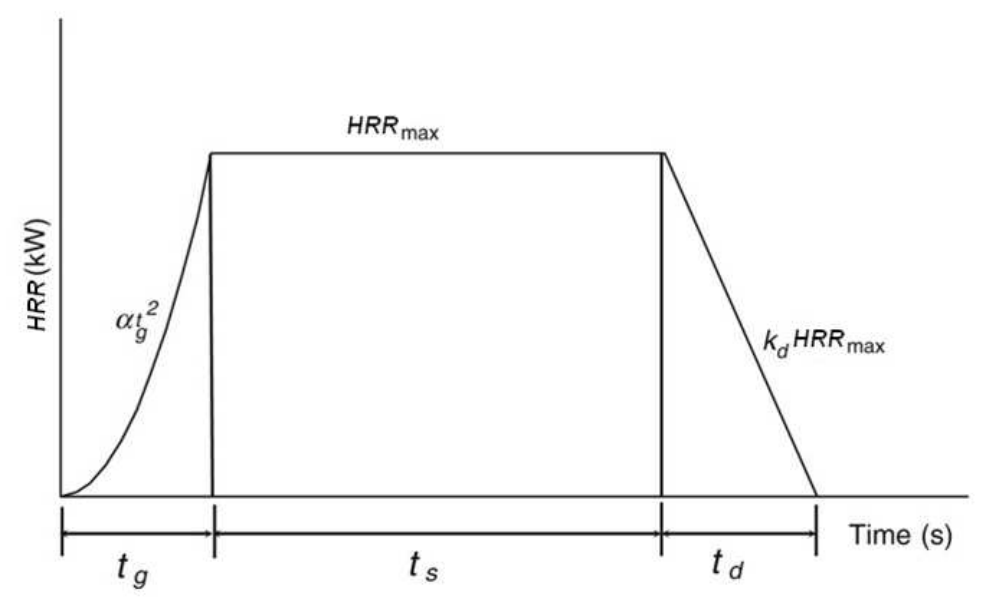

Figure 3. Illustration of the HRR History in a NFSC Fire

In a NFSC fire, at the growth stage, the $H R R$ is given by

$$
H R R=\alpha t^{2}
$$

the fire growth time $t_{g}$ is given by

$$
t_{g}=\sqrt{\frac{H R R_{\max }}{\alpha}}
$$

and the fuel energy consumed at the fire growth stage, $Q_{g}$, is

$$
Q_{g}=\int_{0}^{t_{g}} \alpha t^{2} d t=\frac{\alpha t_{g}^{3}}{3}
$$

where, $\alpha$ is the fire intensity coefficient, taken as $0.00293,0.0117$ and 0.0466 for slow, medium and fast growth fires, respectively.

The duration time of steady burning in a NSFC fire is given by

$$
t_{s}=\frac{0.7 q_{f} A_{f}-Q_{g}}{H R R_{\max }}
$$

and the duration of decaying stage is given by 
$t_{d}=\frac{0.6 q_{f} A_{f}}{H R R_{\max }}$

where, $q_{f}, A_{f}$ are design fire load density and floor area, respectively; and $H R R_{\max }$ is the maximum heat release rate, for ventilation controlled fires [1],

$H R R_{\max }=1500 A_{o} \sqrt{H_{o}}$

where, $A_{o}=W_{o} H_{o}$ is the area of the ventilation opening, in which $W_{o}$ and $H_{o}$ are the width and height, respectively. For fuel-controlled fires, EC1 [2] gives some values of maximum heat release rates for different occupancies.

\subsubsection{Heat loss due to convective flow $\left(\dot{q}_{o, c}\right)$}

Pressure in a compartment fire is essentially atmospheric, and flows occur at openings due to hydrostatic pressure differences. The mass rates of out and in flows are calculated by [1]

$\dot{m}_{g a s}=\frac{2}{3} C_{d} W_{o} \rho_{\infty}\left[2 g \frac{T_{\infty}}{T_{f}}\left(1-\frac{T_{\infty}}{T_{f}}\right)\right]^{1 / 2}\left(H_{o}-X_{N}\right)^{3 / 2}$

And

$\dot{m}_{\text {air }}=\frac{2}{3} C_{d} W_{o} \rho_{\infty}\left[2 g\left(1-\frac{T_{\infty}}{T_{f}}\right)\right]^{1 / 2}\left(X_{N}-X_{d}\right)^{1 / 2}\left(X_{N}+X_{d} / 2\right)$

, respectively. The heat loss due to replacement of hot gases by cold at openings is calculated by

$\dot{q}_{o, c}=\dot{m}_{\text {gas }} c_{p} T_{f}-\dot{m}_{\text {air }} c_{p} T_{\infty}$

The flow coefficient, $C_{d}$, is approximately 0.7 . The neutral plane height, $X_{N}$, can be approximated as the half height of the opening. For post-flashover fires, the height of the interface $X_{d}$ is approximately zero. Taken those values into Eq. 12, the inflow mass rate for post-flashover fires can be approximated as

$\dot{m}_{\text {air }}=0.5 A_{o} \sqrt{H_{o}}$

In many calculations [1], the mass rate of outflow is taken as equal to the mass rate of inflow given by Eq. 14. Correspondingly, the heat loss due to replacement of hot gases by cold is calculated by

$q_{o, c} \approx 0.5 A_{o} \sqrt{H_{o}} c_{p}\left(T_{f}-T_{\infty}\right)$

where, $c_{p}$ is the specific heat of the gas; $T_{f}$ and $T_{\infty}$ are fire and environment temperatures, respectively. 


\subsubsection{Heat loss by radiation through the openings $\left(\dot{q}_{o, r}\right)$}

The heat loss by radiation through the openings of a fire compartment is usually calculated by adopting homogeneous gray gas approximations for fire environment and using Stefan-Boltzmann law, that,

$\dot{q}_{o, r}=A_{o} \varepsilon_{f} \sigma\left(T_{f}^{4}-T_{\infty}^{4}\right)$

where, $\varepsilon_{f}$ is the effective emissivity of the gases within the compartment, which can be calculated from

$\varepsilon_{f}=1-e^{-\kappa L}$

where, $\kappa$ is the emission coefficient, usually taken as $1.1 \mathrm{~m}^{-1}$ [9]; and $L$ is the mean beam length for the enclosure, which is approximated as the height of the compartment.

\subsubsection{Heat loss through wall $\left(\dot{q}_{w}\right)$}

The heat transfer into the boundary surface of a compartment occurs by convection and radiation from the enclosure, and then conduction through the walls. In calculating heat transfer from fire to boundary surface $\left(\dot{q}_{w}\right)$, the following assumptions are adopted,

- In radiation calculation, the fire and the boundary surface are represented as two infinitely parallel grey planes that the view factor is taken as unit;

- In unsteady conduction calculation, The boundaries (walls, ceiling and floor) are usually assumed to be semi-infinite solids

Theoretically, for semi-infinite behavior, the exposure time must be less than the penetration time which for a slab exposed to a Dirichlet boundary condition is about $\frac{1}{\alpha_{w}}\left(\frac{d_{w}}{4}\right)^{2}[1]$. Here, $\alpha_{w}=k_{w} /\left(\rho_{w} c_{w}\right)$ is the thermal diffusivity of the slab, in which $k_{w}, \rho_{w}$ and $c_{w}$ are conductivity, density and specific heat, respectively. $d_{w}$ is the thickness of the slab. In practice, if the thickness of a slab is greater than $2 \sqrt{\alpha_{w} t}$, the semi-infinite solid assumption is used $[1,12]$. In the proposed model, however, the semi-infinite solid assumption is not adopted, that the heat transfer from unexposed surfaces of compartment boundaries to outside environment is considered.

The governing equation for $1 \mathrm{D}$ wall conduction is given by

$\frac{\partial^{2} T_{w}(x, t)}{\partial x^{2}}=\frac{1}{\alpha_{w}} \frac{\partial T_{w}(x, t)}{\partial t}$

At fire and environment exposed sides, the Neumann boundary conditions are given by Eq. 19 and Eq. 20, respectively.

$\dot{q}_{w}=-k_{w} \frac{\partial T_{w}(0, t)}{\partial x}=\left(h_{c, l}+h_{r, l}\right)\left[T_{f}-T_{w}(0, t)\right]$ 
$-k_{w} \frac{\partial T_{w}\left(d_{w}, t\right)}{\partial x}=\left(h_{c, r}+h_{r, r}\right)\left[T_{w}\left(d_{w}, t\right)-T_{\infty}\right]$

Here, $T_{w}(0, t)$ and $T_{w}\left(d_{w}, t\right)$ are temperatures of fire and environment exposed surfaces, respectivly; $h_{c, l}$ and $h_{c, r}$ are convective heat transfer coefficients at fire and environment exposed surfaces, taken as $35 \mathrm{~W} /\left(\mathrm{m}^{2} \mathrm{~K}\right)$ and $9 \mathrm{~W} /\left(\mathrm{m}^{2} \mathrm{~K}\right)$ [2], respectively; and $h_{r, l}$ and $h_{r, r}$ are radiative heat transfer coefficients at fire and environment exposed surfaces, given by Eq. 21 and Eq. 22, respectively.

$$
\begin{aligned}
& h_{r, l}=\varepsilon_{r e s} \sigma\left[T_{f}^{2}+T_{w}(0, t)^{2}\right]\left[T_{f}+T_{w}(0, t)\right] \\
& h_{r, r}=\varepsilon_{w} \sigma\left[T_{\infty}^{2}+T_{w}\left(d_{w}, t\right)^{2}\right]\left[T_{\infty}+T_{w}\left(d_{w}, t\right)\right]
\end{aligned}
$$

Here, $\varepsilon_{\text {res }}$ is the resultant emissivity at fire exposed surface, given by

$$
\varepsilon_{r e s}=\frac{1}{1 / \varepsilon_{f}+1 / \varepsilon_{w}-1}
$$

in which, $\varepsilon_{w}$ is the emissivity of the wall.

\subsubsection{Heat storage in gas volume $\left(\dot{q}_{g}\right)$}

The heat stored in the gas volume within the compartment is calculated by

$\dot{q}_{g}=\rho_{\infty} c_{p} V_{g} \frac{\Delta T_{f}}{\Delta t}$

where, $\rho_{\infty}$ is the density of the gas; and $V_{g}$ is the gas volume.

\subsubsection{Heat absorbed by steel members $\left(\dot{q}_{s}\right)$}

For bare steel, using lumped capacitate method, the heat absorbed by the steel members within the compartment is calculated by

$\dot{q}_{s}=c_{s} m_{s} \frac{\Delta T_{s}}{\Delta t}$

where, $c_{s}$ is the specific heat of steel; $m_{s}$ is the total mass of steel members; and $T_{s}$ is the average steel temperature.

For insulated steel, 1D condensed model (Figure 2) is adopted to calculate heat transfer. At fire-insulation interface, the Neumann boundary condition is adopted. By lumped capacitance concept, the boundary condition at the steel-insulation interface is given by

$$
-k_{i} \frac{\partial T\left(d_{i}, t\right)}{\partial x}=\frac{c_{s} \rho_{s}}{A_{i} / V_{s}} \frac{\partial T\left(d_{i}, t\right)}{\partial t}
$$


$T_{s}=T\left(d_{i}, t\right)$

where, $T\left(d_{i}, t\right)$ is the temperature of insulation at steel-insulation interface; $c_{s} \rho_{s}$ is the volumetric specific heat of steel; $A_{i} / V_{s}$ is the section factor, in which $A_{i}$ is the appropriate area of the fire insulation, and $V_{s}$ is the volume of steel; and $d_{i}$ is the thickness of the insulation.

For steel members insulated by thin, light weight coatings, the heat absorbed by the coatings are usually ignored, that the heat absorbed by the members are calculated by Eq. 25 .

\section{SIMULATING THE MODIFIED ONE-ZONE MODEL BY FEM}

\subsection{Numerical Tool}

The proposed model given above can be solved using technologies like finite differential method (FDM) and finite element method (FEM). In this paper, the FEM program ANSYS with powerful capacity to solve steady-state or transient heat transfer problems, is employed to simulate the proposed model. Validation of the program has been conducted by many works, e.g. [7, 13].

\subsection{Basic Elements}

\subsubsection{LINK32-2D conduction bar}

LINK 32 is a uniaxial element with the ability to conduct heat between its nodes. The element has a single degree of freedom, temperature, at each node point. The conducting bar is applicable to a 2D, steady-state or transient thermal analysis.

The element is defined by two nodes, a cross-sectional area, and the material properties. The thermal conductivity is in the element longitudinal direction. Heat generation rates may be input as element body loads at the nodes.

\subsubsection{LINK34-convection link}

LINK34 is a uniaxial element with the ability to convect heat between its nodes. The element has a single degree of freedom, temperature, at each node point. The convection element is applicable to a $2 \mathrm{D}$ or $3 \mathrm{D}$, steady-state or transient thermal analysis. The element is defined by two nodes, a convection surface area, two empirical terms, and a film coefficient.

\subsubsection{LINK31-radiation link}

LINK31 is a uniaxial element which models the radiation heat flow rate between two points in space. The link has a single degree of freedom, temperature, at each node. The radiation element is applicable to a 2D or 3D, steady-state or transient thermal analysis.

The element is defined by two nodes, a radiating surface area, a geometric form factor, the emissivity, and the Stefan-Boltzmann constant. 


\subsubsection{MASS71-thermal mass}

MASS71 is a point element with one degree of freedom, temperature, at the node. The element may be used in a transient thermal analysis to represent a body having thermal capacitance capability but negligible internal thermal resistance, that is, no significant temperature gradients within the body. The lumped thermal mass element is applicable to a $1 \mathrm{D}, 2 \mathrm{D}$, or $3 \mathrm{D}$ steady-state or transient thermal analysis.

The lumped thermal mass element is defined by one node and a thermal capacitance.

\subsection{FEM Model}

Figure 4 illustrates the FEM model. The heat source is modeled by a perfect conductor, which is represented by one LINK32 element. The heat generation rate of the source is input as HRR specified by NFSC. The compartment boundaries and the insulation coatings of the steel members are modeled using LINK32. Convection and radiation at fire or environment exposed surfaces are modeled using LINK34 and LINK31, respectively. Gas and steel volumes are modeled using MASS71. Radiation at opening is modeled using LINK31. Convection at opening by mass exchange is modeled using LINK34 with film coefficient of $c_{p} \dot{m}_{g a s} / A_{o}$.

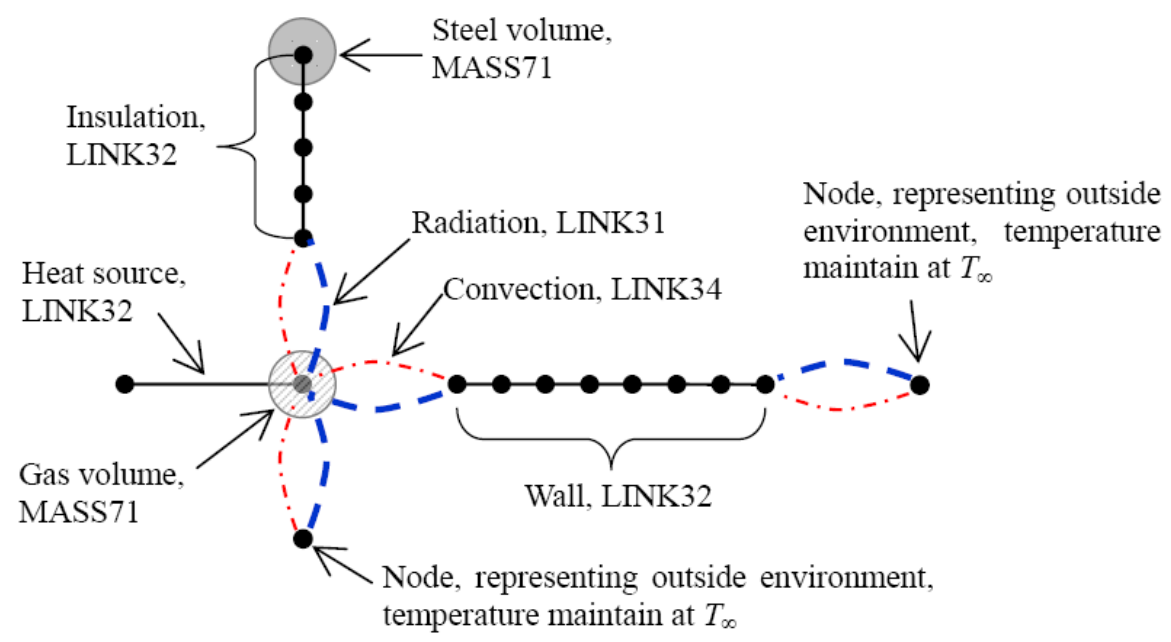

Figure 4. Illustration of the FEM Model

\section{CASE STUDIES}

\subsection{Verification of FEM Model}

Not including steel members in the proposed model, the results predicted by the proposed model simulated by FEM are compared with those predicted by the program OZone [4], Lie method [14] and EC1 parameter fire [2].

In the study, a compartment with dimensions of $3 \mathrm{~m}$ width, $4 \mathrm{~m}$ length and $2.7 \mathrm{~m}$ height are considered. The compartment has a vent of $2 \mathrm{~m}$ width and $1 \mathrm{~m}$ height. The compartment boundaries are made of normal weight concrete (NWC) with thickness of $200 \mathrm{~mm}$. The properties of NWC are $\rho_{w}=2300 \mathrm{~kg} / \mathrm{m}^{3}, c_{w}=1000 \mathrm{~J} /(\mathrm{kg} \mathrm{K})$, and $k_{w}=1.6 \mathrm{~W} /(\mathrm{m} \mathrm{K})$. The floor fire load density is $800 \mathrm{MJ} / \mathrm{m}^{2}$ and the fire intensity coefficient is 0.0117 . The maximum heat release rate per unit area for fuel controlled fire is taken as $250 \mathrm{~kW} / \mathrm{m} 2$. Correspondingly, the calculated $H R R_{\max }$ for fuel and ventilation controlled fires are $2.25 \mathrm{MW}$ and 3.0 MW respectively. 
Figure 5 shows the comparison among the results of fire temperatures predicted by different methods. The FEM model and OZone give consistent results for both fuel $\left(H R R_{\max }=2.25 \mathrm{MW}\right)$ and ventilation $\left(H R R_{\max }=3 \mathrm{MW}\right)$ controlled fires, whilst in the heating phases the fire temperatures predicted by the FEM model are slightly higher than those predicted by OZone. The differences among the results by FEM model and OZone are due to different mathematic technologies adopted by them in solving sub-models in one zone post-flashover fire model [4]. Results by Lie method agree well with those by FEM model using $H R R_{\max }=2.25 \mathrm{MW}$ in the heating phases. Lie method and EC1 parameter fire give same results for fuel and ventilation controlled fires.

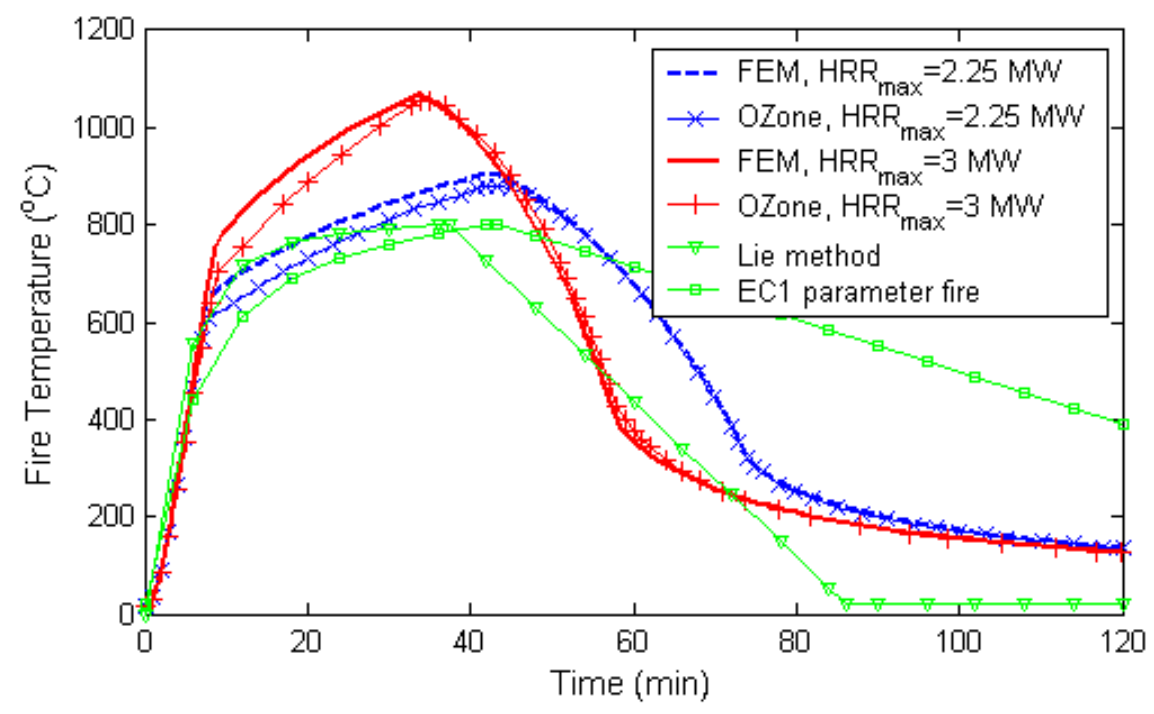

Figure 5. Comparison among Results of Fire Temperatures Predicted by Different Methods

\subsection{Bare Steel Members}

The fire compartment is $4.8 \mathrm{~m}$ width, $6.0 \mathrm{~m}$ depth and $3.6 \mathrm{~m}$ height. The compartment boundaries are made of $200 \mathrm{~mm}$ gypsum board, the properties of which are $\rho_{w}=800 \mathrm{~kg} / \mathrm{m}^{3}, c_{w}=1700 \mathrm{~J} /(\mathrm{kg} \mathrm{K})$ and $k_{w}=0.2 \mathrm{~W} /(\mathrm{m} \mathrm{K})$. The compartment has a vent of $4.8 \mathrm{~m}$ width and $1.8 \mathrm{~m}$ height. The floor fire load density is $600 \mathrm{MJ} / \mathrm{m}^{2}$ and the fire intensity coefficient is 0.0117 . Including steel members in the FEM model, the effect of steel members within the compartment on gas and steel temperatures are investigated. Ventilation controlled fires are considered in the following studies. The cross section of the steel member is $\mathrm{H} 300 \times 300 \times 10 \times 15$ and the length of the member is taken as the height of the compartment.

Figure 6 shows the results of gas temperatures with different number of steel members in the compartment. The more the number of steel members, the lower is the gas temperatures. For the case with 4 steel members, the predicted maximum gas temperature is about $46{ }^{\circ} \mathrm{C}$ lower than that for the case with no steel member. Figure 7 shows the results of steel temperatures. For the case with no steel in the compartment, the steel temperature is calculated by solving the 1D condensed heat transfer model (Figure 2) with using the predicted fire curve. The more the number of steel members, the lower is the steel temperatures. For the case with no steel member, the predicted maximum steel temperature is about $31{ }^{\circ} \mathrm{C}$ higher than that for the case with 4 steel members.

Figures 8 and 9 show the results of steel temperatures for compartments with different floor and opening areas, respectively. Taking $\triangle T_{s, \max }$ as the difference between the maximum steel temperatures for the same compartment with no steel member and with 4 steel members, $\Delta T_{s, \max }$ decreases with compartment floor area increases, and increases with opening area increases. 
Figure 10 shows the results of steel temperatures for compartments with different fire loads. $\triangle$ $T_{s, \max }$ decreases with fire load increases.

For the investigated cases, the maximum value of $\Delta T_{s, \max }$ is $219{ }^{\circ} \mathrm{C}$, which is for the case with $q_{f}=300 \mathrm{MJ} / \mathrm{m}^{2}$ and is shown in Figure 10.

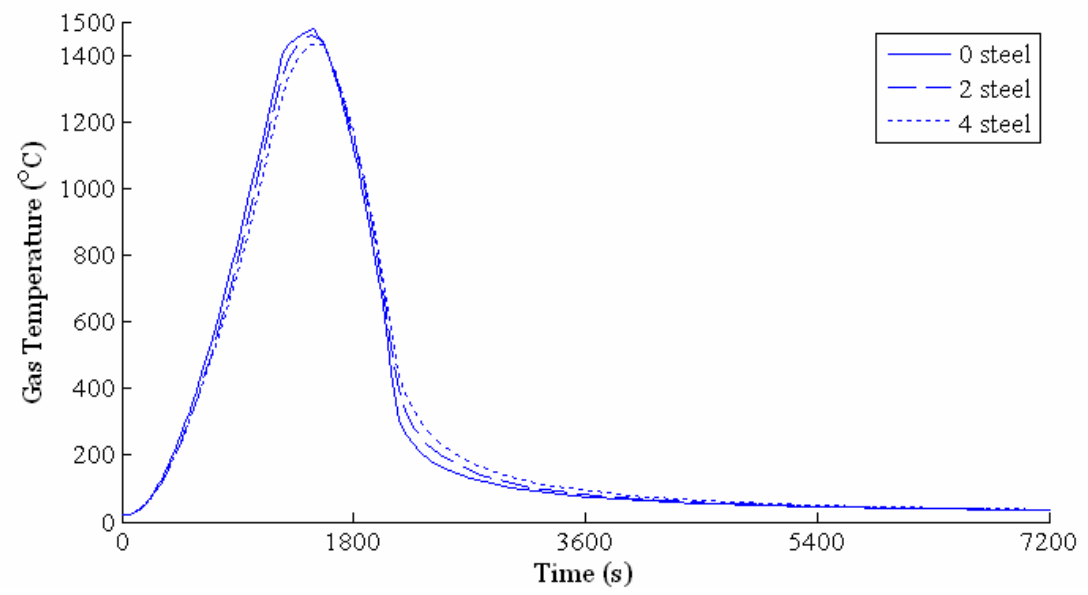

Figure 6. Results of Gas Temperatures for a Compartment with Different Number of Steel Members in it

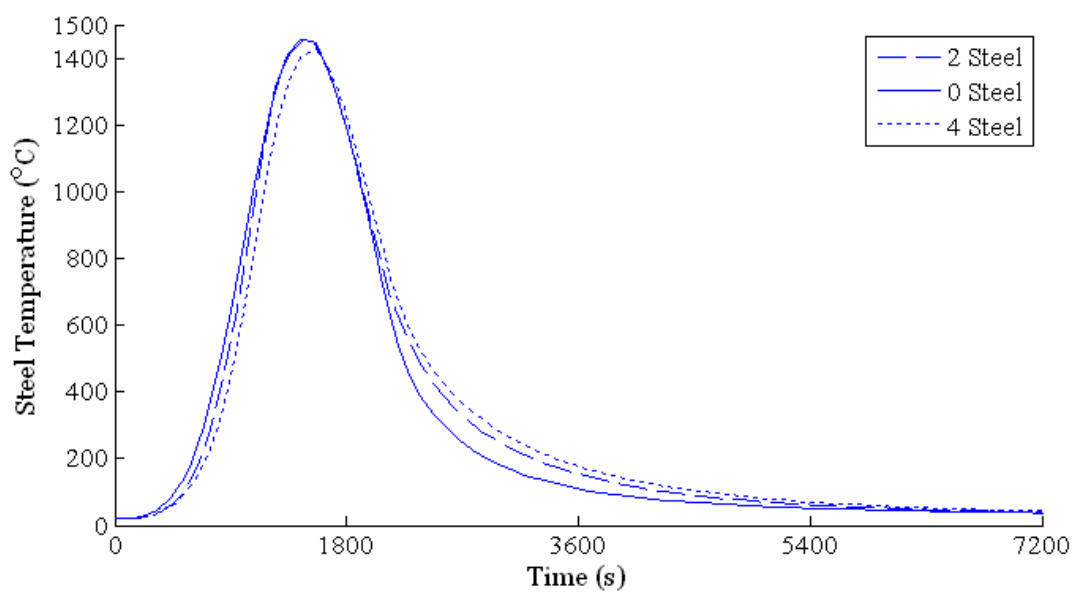

Figure 7. Results of Steel Temperatures for a Compartment with Different Number of Steel Members in it

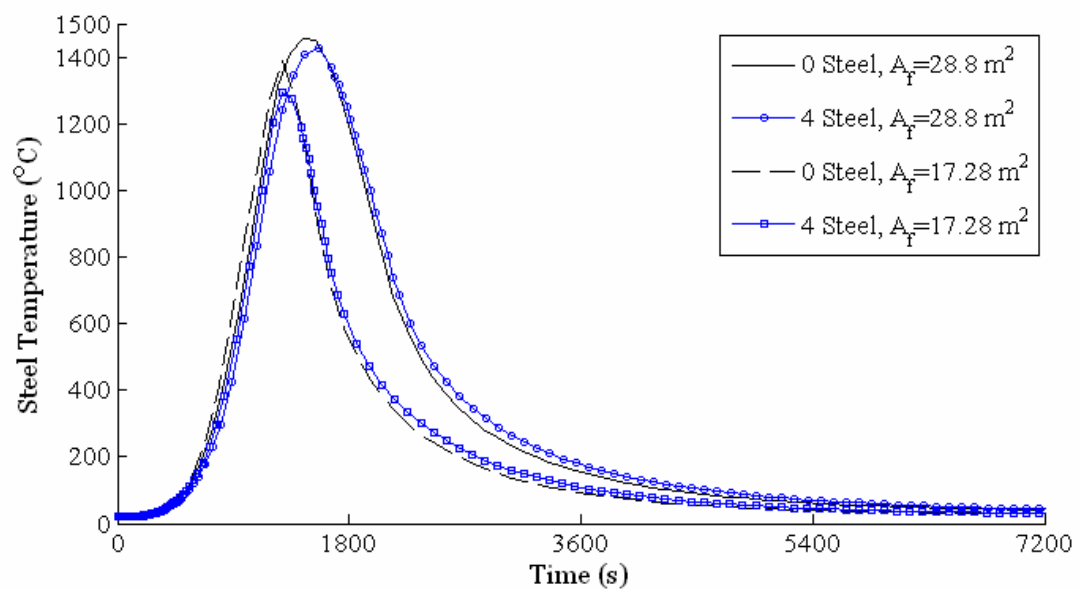

Figure 8. Results of Steel Temperatures for Compartments with Different Floor Areas 


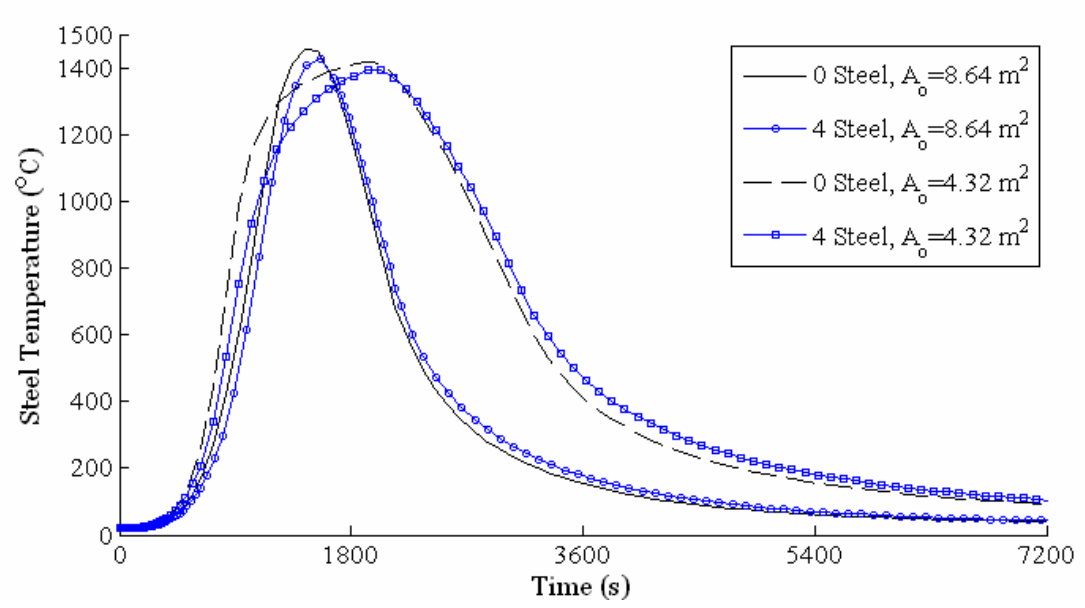

Figure 9. Results of Steel Temperatures for Compartments with Different Opening Areas

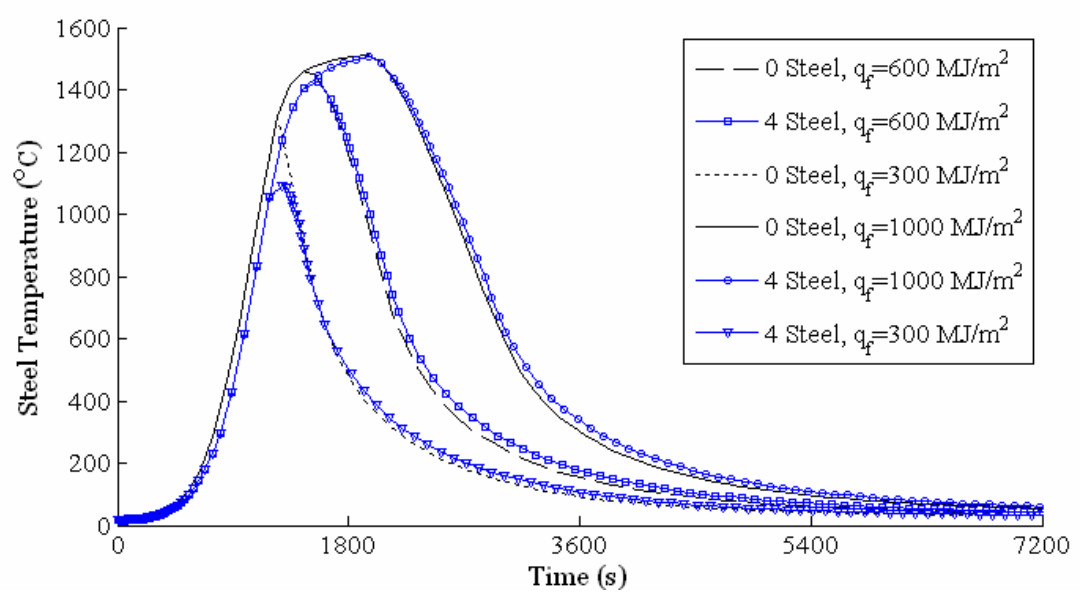

Figure 10. Results of Steel Temperatures for Compartments with Different Fire Loads

\subsection{Insulated Steel Members}

Figures 11 to 14 show the results for insulated steel members in fire compartments. The insulation material is a commonly used SFRM, the properties of which are $\rho_{i}=250 \mathrm{~kg} / \mathrm{m}^{3}, c_{i}=800 \mathrm{~J} /(\mathrm{kg} \mathrm{K})$ and $k_{i}=0.12 \mathrm{~W} /(\mathrm{m} \mathrm{K})$. The difference between the maximum steel temperatures for cases with no insulated member and with 4 insulated member, $\Delta T_{s, \max }$, decreases with floor area decreases, opening area increases, fire load decreases, and insulation thickness increases.

For the investigated cases, the maximum value of $\Delta T_{s, \max }$ is $38{ }^{\circ} \mathrm{C}$, which is for the case with $A_{0}=4.32 \mathrm{~m}^{2}$ and is shown in Figure 12 . 


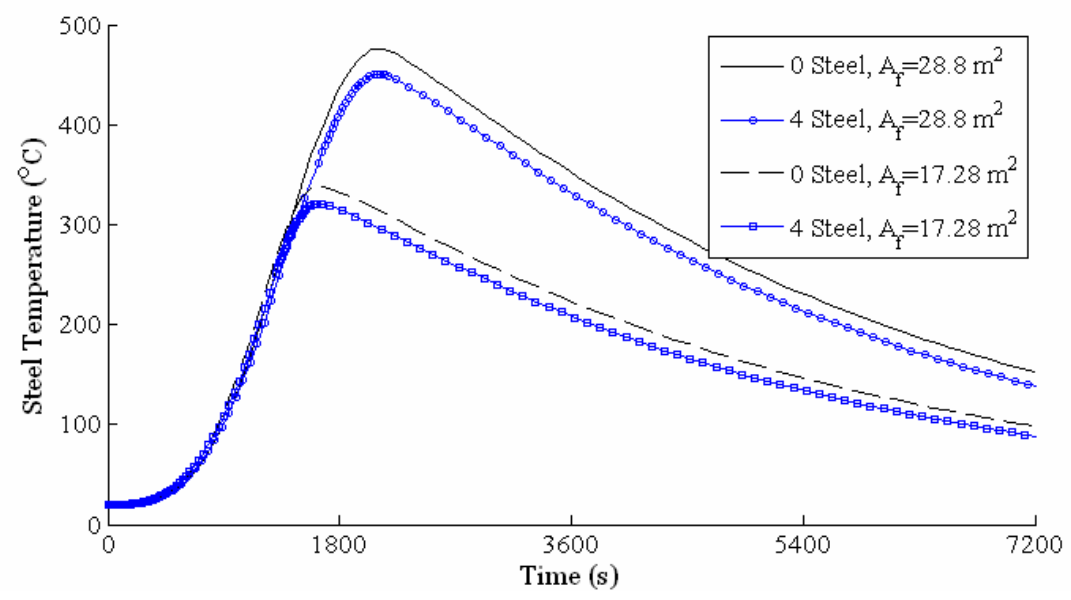

Figure 11. Results of Steel Temperatures of Insulated Members in Compartments with Different Floor Areas

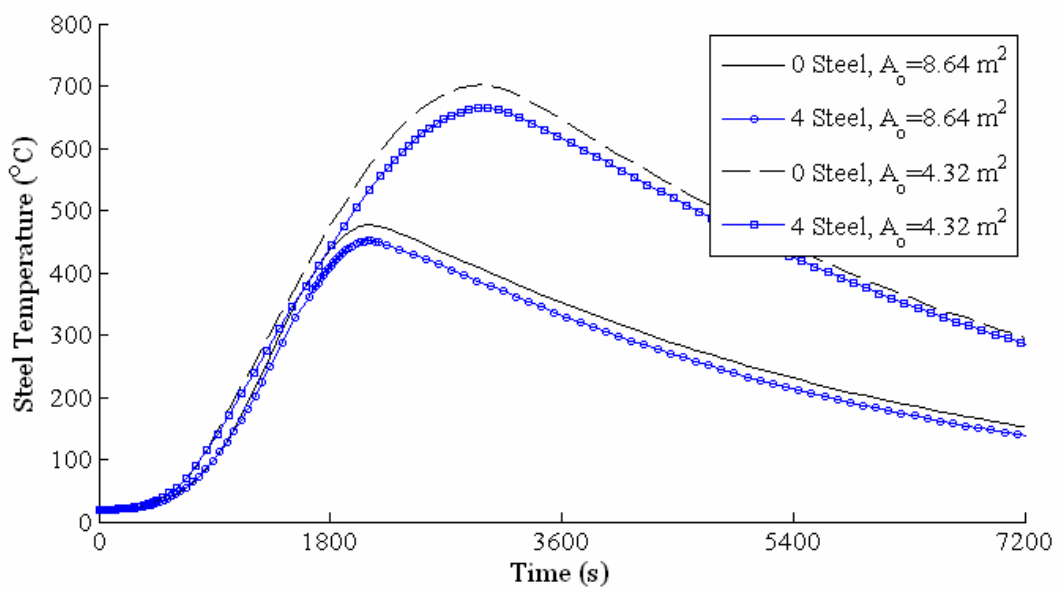

Figure 12. Results of Steel Temperatures of Insulated Members in Compartments with Different Opening Areas

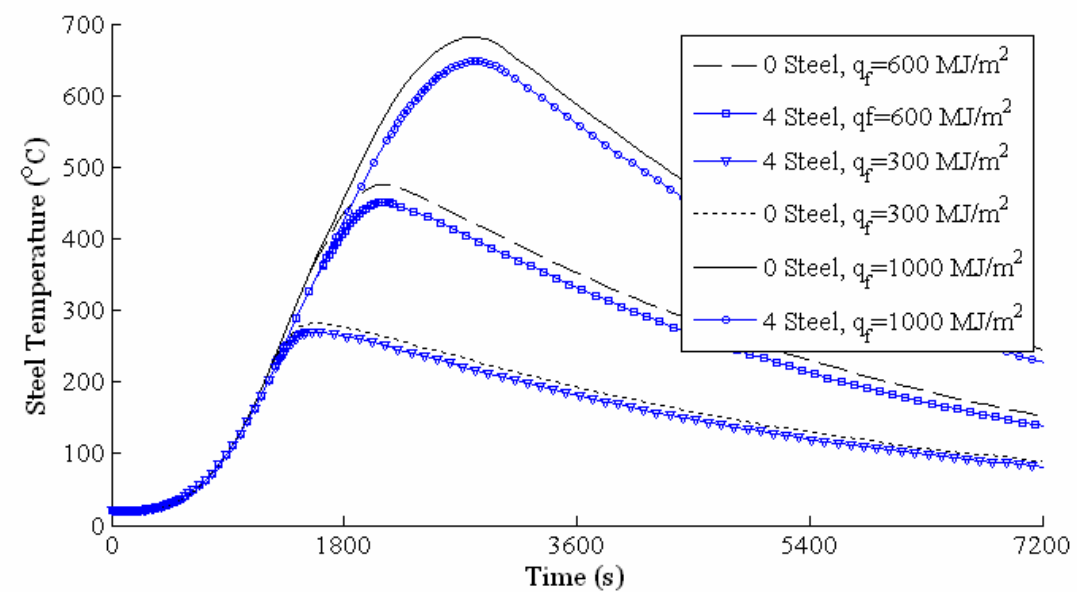

Figure 13. Results of Steel Temperatures of Insulated Members in Compartments with Different Fire Loads 


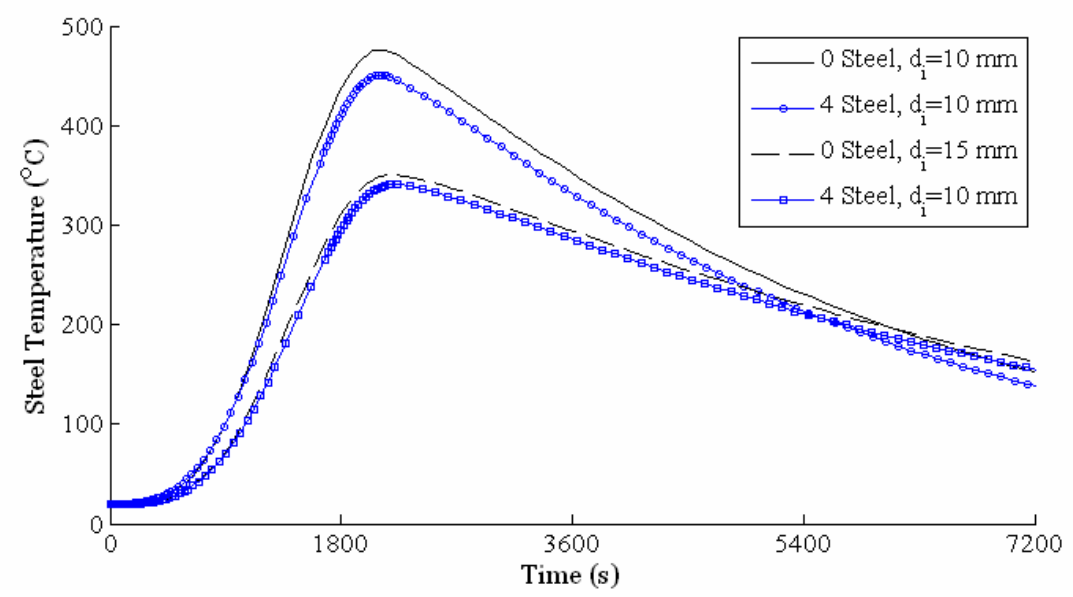

Figure 14. Results of Steel Temperatures of Insulated Members with Different Insulation Thicknesses

\section{DESIGN EXAMPLE}

Problem: 4 steel columns are located at different corners of a fire compartment in an office building. The compartment is $4.8 \mathrm{~m}$ width, $6.0 \mathrm{~m}$ length and $3.6 \mathrm{~m}$ height, and is made of gypsum board with thickness of $200 \mathrm{~mm}$. The compartment has a window with dimensions of $2.4 \mathrm{~m}$ width and $1.8 \mathrm{~m}$ height. The compartment has two fire doors which are assumed to be closed in fire condition. The design fire load density is taken as $600 \mathrm{MJ} / \mathrm{m}^{2}$. The dimensions of the columns are designed to be $\mathrm{H} 400 \times 400 \times 15 \times 20$. Take column failure temperature as $550{ }^{\circ} \mathrm{C}$, determine the fire protection of the columns.

Design by the proposed model: The calculated bare steel column temperature obtained through solving the modified one-zone model, $T_{s, \max }$, is close to the fire temperature and taken as $1356{ }^{\circ} \mathrm{C}$. Adopting the commonly used SFRM considered above as the fire protection material, the calculated minimum insulation thickness is $9.7 \mathrm{~mm}\left(T_{s, \max }=548{ }^{\circ} \mathrm{C}<550{ }^{\circ} \mathrm{C}\right)$.

Design by the current model: The calculated fire temperature obtained through solving the traditional one-zone model is $1422{ }^{\circ} \mathrm{C}$. Adopting the commonly used SFRM, the calculated minimum insulation thickness through solving the 1D condensed heat transfer model given in Figure 2 is $10.8 \mathrm{~mm}\left(T_{s, \max }=549{ }^{\circ} \mathrm{C}<550{ }^{\circ} \mathrm{C}\right)$

The difference between the minimum insulation thickness determined by the traditional and proposed model is $1.1 \mathrm{~mm}$.

\section{CONCLUSIONS}

In real conditions, the steel members in a fire compartment will absorb a portion of the heat released by combustion. That position of heat is the reason that causes steel temperature elevation, and in turn it has effect of cooling the compartment. In this paper, a modified one-zone model has been proposed for calculating the temperature of steel members in post-flashover fires. Based on the results of this study, the following conclusions can be drawn:

- The proposed model has capacity of modeling the heating mechanism of steel members in post-flashover fires, which is recommended for practical usage. Based on the proposed model, computing program or analytical formulae can be derived for daily design work. 
- The proposed model can yield more economical fire resistance design than the current model. For the considered design example of an office building, the proposed model can save $1.1 \mathrm{~mm}$ fire protection material for each steel column.

- For fire compartments with bare steel members, the steel heat sink effect is greater for compartments with smaller floor area, larger opening, lower fire load density, and more steel members. Correspondingly, the over-predictions of the maximum steel temperatures by the current model are comparatively more severe for those compartments.

- For fire compartments with insulated steel members, the steel heat sink effect is greater for compartments with larger floor area, smaller opening, higher fire load density, and more steel members with thinner insulation. Correspondingly, the over-predictions of the maximum steel temperatures by the current model are comparatively more severe for those compartments.

\section{NOMENCLATURE}

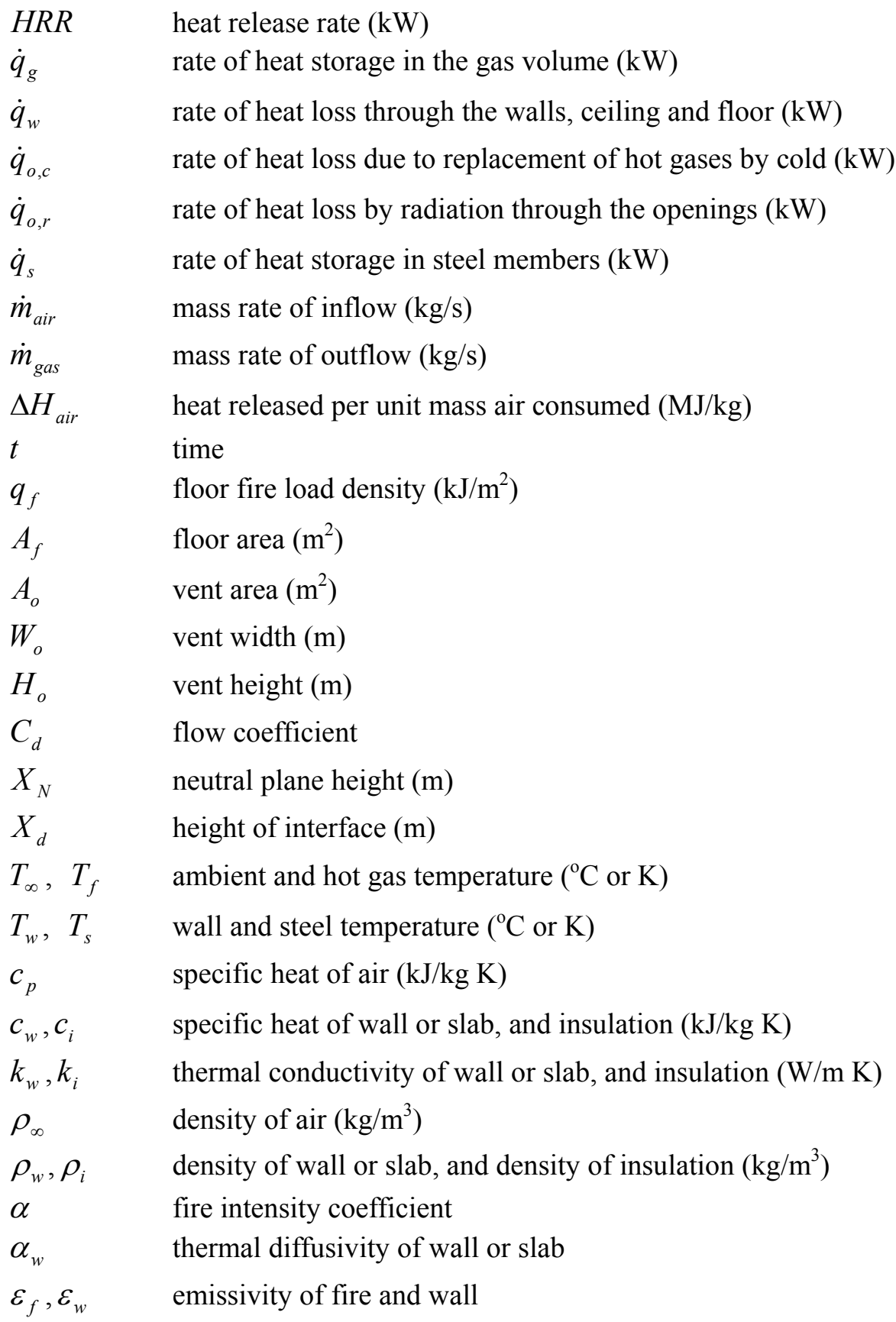




$\begin{array}{ll}\sigma & \text { Stefan-Boltzmann constant } \\ d_{w}, d_{i} & \text { wall or slab thickness, and insulation thickness }(\mathrm{mm}) \\ h_{c}, h_{r} & \text { convective and radiative heat transfer coefficient }\left(\mathrm{W} / \mathrm{m}^{2} \mathrm{~K}\right)\end{array}$

\section{REFERENCES}

[1] Drysdale, D., "An introduction to Fire Dynamics", 2nd Edition, John Wiley and Sons, 1999.

[2] EC1-1-2. Eurocode 1: Actions on Structures - Part 1-2: General Actions - Actions on Structures Exposed to Fire, British Standards Institution (BSI), 2002.

[3] Babrauskas, V., "COMPF2: A Program for Calculating Post-flashover Fire Temperatures”, NBS Technical Note 991, National Bureau of Standards, 1979.

[4] Cadorin, J.F. and Franssen, J.M., "A Tool to Design Steel Elements Submitted to Compartment Fires - OZone V2, Part 1: Pre- and Post-flashover Compartment Fire Model", Fire Safety Journal, 2003, Vol. 38, pp. 395-427.

[5] Jones, W.W., Peacock, R.D., Forney, G.P. and Reneke, P.A., "CFAST - Consolidated Model of Fire Growth and Smoke Transport (Version 6): Technical Reference Guide", NIST Special Publication 1026, Gaithersburg : National Institute of Standard and Technology, 2009.

[6] McGrattan, K., McDermott, R., Hostikka, S. and Floyd, J., "Fire Dynamics Simulator (Version 5) User's Guide", NIST Special Publication 1019-5, National Institute of Standards and Technology (NIST), 2010.

[7] Li, G.Q. and Zhang, C., "Thermal Response to Fire of Uniformly Insulated Steel Members: Background and Verification of the Formulation Recommended by Chinese Code CECS200", Advanced Steel Construction, 2010, Vol. 6, pp. 788-802.

[8] Zhang, C. and Li, G.Q., "Thermal Response of Steel Columns Exposed to Localized Fires - Numerical Simulation and Comparison with Experimental Results", Journal of Structural Fire Engineering, 2011, Vol. 2, pp. 311-7.

[9] Pettersson, O., Magnusson, S.E. and Thor, J., "Fire Engineering Design of Steel Structures", Swedish Institute of Steel Construction, Publication 50, Stockholm, 1976.

[10] Buchanan, A.H., "Structural Design for Fire Safety", John Wiley and Sons, Ltd, 2001.

[11] Babrauskas, V., SFPE Handbbok of Fire Protection Engineering, 3rd edition, Section 3-1:Heat Release Rates, Society of Fire Protection Engineers, 2002.

[12] McCaffrey, B.J., Quintiere, J.G. and Harkleroad, M.F., "Estimating Room Temperatures and Likelihood of Flashover using Fire Test Data Correlations", Fire Technology, 1981, Vol. 17, pp. 98-119.

[13] Zhang, C., Li, G.Q. and Wang, Y.C., "Sensitivity Study on using Different Formulas for Calculating the Temperatures of Insulated Steel Members in Natural Fires", Fire Technology, 2012, Vol. 48, pp. 343-66.

[14] Lie, T.T., "Fire Temperature-time Relations", SFPE Handbook of Fire Protection Engineering, 3rd Edition, Society of Fire Protection Engineers, 2002. 